\title{
Human Coronavirus NL63 Open Reading Frame 3 encodes a virion-incorporated N-glycosylated membrane protein
}

\author{
Marcel A Müller ${ }^{1,2}$, Lia van der Hoek ${ }^{3}$, Daniel Voss², Oliver Bader², Dörte Lehmann², Axel R Schulz², \\ Stephan Kallies ${ }^{1}$, Tasnim Suliman ${ }^{4}$, Burtram C Fielding ${ }^{4}$, Christian Drosten ${ }^{1 *}$, Matthias Niedrig ${ }^{2}$
}

\begin{abstract}
Background: Human pathogenic coronavirus NL63 (hCoV-NL63) is a group 1 (alpha) coronavirus commonly associated with respiratory tract infections. In addition to known non-structural and structural proteins all coronaviruses have one or more accessory proteins whose functions are mostly unknown. Our study focuses on hCoV-NL63 open reading frame 3 (ORF 3) which is a highly conserved accessory protein among coronaviruses.

Results: In-silico analysis of the 225 amino acid sequence of hCoV-NL63 ORF 3 predicted a triple membranespanning protein. Expression in infected CaCo-2 and LLC-MK2 cells was confirmed by immunofluorescence and Western blot analysis. The protein was detected within the endoplasmatic reticulum/Golgi intermediate compartment (ERGIC) where coronavirus assembly and budding takes place. Subcellular localization studies using recombinant ORF 3 protein transfected in Huh-7 cells revealed occurrence in ERGIC, Golgi- and lysosomal compartments. By fluorescence microscopy of differently tagged envelope (E), membrane $(M)$ and nucleocapsid $(N)$ proteins it was shown that ORF 3 protein colocalizes extensively with $E$ and $M$ within the ERGIC. Using N-terminally FLAG-tagged ORF 3 protein and an antiserum specific to the C-terminus we verified the proposed topology of an extracellular N-terminus and a cytosolic C-terminus. By in-vitro translation analysis and subsequent endoglycosidase $\mathrm{H}$ digestion we showed that ORF 3 protein is N-glycosylated at the N-terminus. Analysis of purified viral particles revealed that ORF 3 protein is incorporated into virions and is therefore an additional structural protein.
\end{abstract}

Conclusions: This study is the first extensive expression analysis of a group 1 hCoV-ORF 3 protein. We give evidence that ORF 3 protein is a structural N-glycosylated and virion-incorporated protein.

\section{Background}

The human Coronavirus (hCoV)-NL63 constitutes one of four circulating prototypic human Coronaviruses (CoV) [1]. HCoV-NL63 infection causes upper and lower respiratory tract disease and is globally widespread, particularly among children under the age of six years [2-4]. It was shown to be associated with croup $[5,6]$.

$\mathrm{CoV}$ belong to the Nidovirales. The $\mathrm{CoV}$ genome consists of a 27 to $33 \mathrm{~kb}$ positive single-stranded RNA which is 5'-capped and 3'-polyadenylated [7]. The genome of hCoV-NL63 comprises 27,553 nt and has a gene

\footnotetext{
* Correspondence: drosten@virology-bonn.de

${ }^{1}$ University of Bonn Medical Centre, Sigmund-Freud-Str. 25, D-53127 Bonn,
} Germany

\section{Biomed Central}

(c) 2010 Müller et al; licensee BioMed Central Ltd. This is an Open Access article distributed under the terms of the Creative Commons Attribution License (http://creativecommons.org/licenses/by/2.0), which permits unrestricted use, distribution, and reproduction in any medium, provided the original work is properly cited. $(\mathrm{S})$, open reading frame 3 (ORF 3 ), envelope (E), membrane $(\mathrm{M})$ and the nucleocapsid $(\mathrm{N})$ gene. CoV virions consist of a nucleocapsid core surrounded by an envelope containing three membrane proteins, S, E, and M. $\mathrm{CoV}$ assemble and bud at membranes of the endoplasmic reticulum (ER)-Golgi intermediate compartment (ERGIC) [8,9]. While the budding site of several CoV has been localized at the ERGIC, the viral surface proteins can also be found in downstream compartments of the secretory pathway [8]. M localizes predominantly in the Golgi apparatus $[10,11], \mathrm{S}$ is found along the secretory pathway and at the plasma membrane $[12,13]$, and $E$ is detected in perinuclear regions, the ER and Golgi [14-16]. S and $M$ are typically glycosylated and it was shown that glycosylation plays an important role in the 
generation of bioactive protein conformations and influences fusion activity, receptor binding, and antigenic properties of CoV [17-20].

In addition to the $S, E, M$ and $N$ protein genes, the structural gene portion of $\mathrm{CoV}$ genomes contains a variable number of accessory ORFs. Because these accessory ORFs are not shared between different CoV groups, they are also referred to as group-specific ORFs [21]. Proteins encoded by group-specific ORFs of different $\mathrm{CoV}$ have been shown to influence pathogenesis, virus replication, or host immune response [21-27]. Others may be dispensable for virus replication in cultured cells of primate or rodent origin, as well as in rodent models [26,28,29].

The ORF 3 is the only accessory ORF conserved in all CoVs [30]. Most investigations of its functionality have been done on the example of SARS-CoV ORF 3a. The SARS-CoV ORF 3a protein is expressed in infected cells and patient sera contained antibodies reactive with recombinant ORF 3a antigen. The $\mathrm{N}$-terminal ectodomain was able to induce virus-neutralizing antibodies in rabbits [31]. SARS-CoV ORF 3a protein is a triple-spanning membrane protein with a similar topology as the $M$ protein, and is integrated into virions [32]. Moreover, truncated forms were discovered for recombinantly and virally expressed ORF 3 a protein which could also be detected in virions [33]. Unlike the $M$ protein it is not $\mathrm{N}$-glycosylated but $\mathrm{O}$-glycosylated and it was shown to interact with E, M and S protein [16,34-36]. Subcellular localization of ORF 3 a protein was found to be at the Golgi complex and the plasma membrane where it was also internalized by endocytosis [36]. ORF 3a protein was shown to induce apoptosis [37] and cell cycle arrest [38] and to up-regulate expression of fibrinogen in lung epithelial cells [39]. Although small interfering RNAs targeting the ORF 3a-specific viral subgenomic RNA were able to reduce viral replication [40], deletion of ORF 3a from an infectious cDNA clone had no effect on viral replication in cell culture and mice [28]. Moreover it has been demonstrated that SARS-ORF 3a protein forms a homotetramer through inter-protein disulfide bonds, functionally working as a potassium ion channel that modulates virus release [41]. Very recently it was shown that the ORF 3a protein disrupts the architecture of the Golgi apparatus and might thus be responsible for the formation of vesicular structures in which virus replication takes place [42].

SARS-CoV as a member of CoV group $2 \mathrm{~b}$ (beta) is only distantly related to the human CoV-NL63, a member of group 1b (alpha). For the ORF 3 protein of group 1 (alpha) CoVs investigations have focused on the porcine epidemic diarrhea virus (PEDV, group 1b, alpha) and transmissible gastroenteritis virus (TGEV, group 1a, alpha) that cause enteropathogenic diarrhea in swine
[43]. It was shown that virulence of these viruses could be reduced by altering the ORF 3 gene through cell culture adaptation $[44,45]$. For hCoV-NL63, preliminary experiments suggested that deletion of ORF 3 had little influence on viral replication in cell culture [46]. However, the closely related hCoV-229E has a homologous gene named ORF 4 that is split into two ORFs (4a and $4 \mathrm{~b})$ in cell culture but maintained in all circulating viruses. This suggests an in-vivo function that may not be necessary for viral replication in cell culture [47].

In the present study we characterized the ORF 3 protein of hCoV-NL63. We analyzed the expression and subcellular localization of the ORF 3 protein in virusinfected cells and cells transfected transiently with ORF 3 protein-expressing plasmids. We determined the topology of the ORF 3 protein, characterized its glycosylation, and showed that the ORF 3 protein is a structural protein incorporated into viral particles.

\section{Results and Discussion}

The hCoV-NL63 genome contains an open reading frame (ORF 3) situated between the $S$ and $E$ genes (Figure 1A). Nucleic acid sequence alignments with homologous genes of other CoV from groups alpha, beta and gamma yield nucleotide identities between $30,3 \%$ and $51,9 \%$ (Table within Figure 1A). Amino acid alignments showed highest levels of similarity (62\%) and identity (43\%) between hCoV-NL63 ORF 3 protein and the homologous protein of hCoV-229E [48]. A constant level of similarity was observed across the whole protein. In-silico analysis of potential glycosylation sites and membrane topology suggest properties similar to SARSCoV ORF 3a protein (Figure $1 \mathrm{~B}$ and Table 1). HCoVNL63 encodes a 225 aa protein (approximately $26 \mathrm{kDa}$ ) with three putative transmembrane domains at aa positions 39-61, 70-92 and 97-116, respectively (TMHMM analysis). It has three potential $\mathrm{N}$-glycosylation sites (NXS/T) at aa positions 16, 119 and 126, of which probably only the first is used because the sites at positions 119 and 126 are located inside the predicted transmembrane domains. No O-glycosylation sites are predicted. Nearly half of the protein (108 of 225 aa) forms a hydrophilic $\mathrm{C}$-terminus. These findings are in concordance with earlier data comparing SARS-CoV 3a-like CoV proteins [35].

\section{Expression and subcellular localization of ORF 3 protein in virus-infected cells}

To analyze the expression of ORF 3 protein during viral replication, colon carcinoma cells $(\mathrm{CaCo}-2)$ and Rhesus monkey kidney cells (LLC-MK2) cells were infected with hCoV-NL63 and an immunofluorescence assay (IFA) was done after two and four days, respectively. A rabbit polyclonal antiserum raised against a peptide 


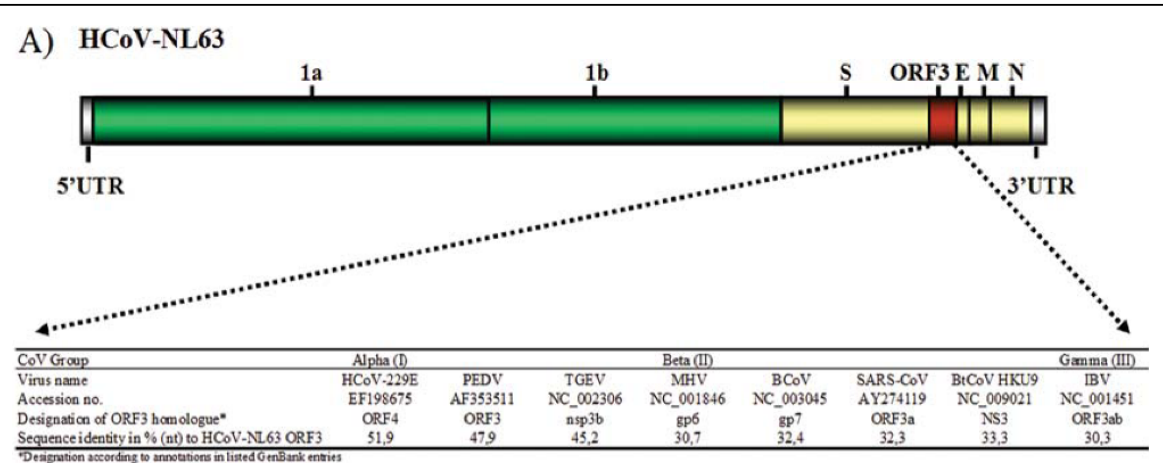

B)

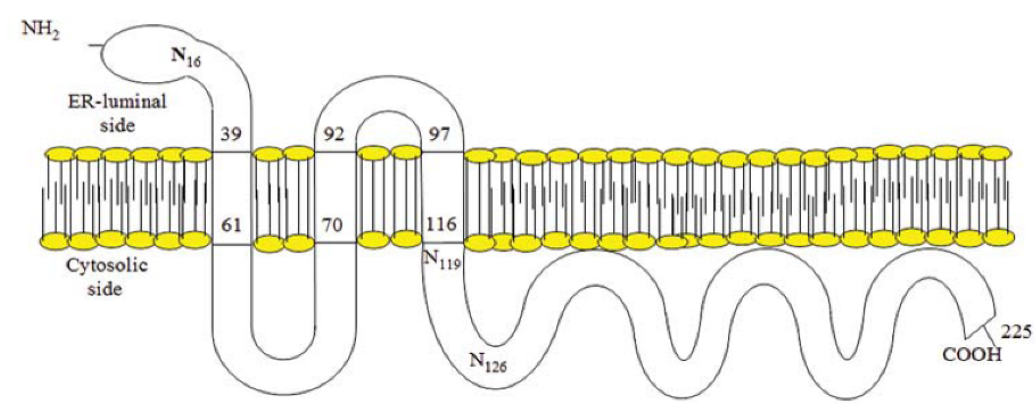

Figure 1 Characteristics of hCoV-NL63 open reading frame 3 and comparison to homologous genes in other coronaviruses. The sequence of ORF 3 (GenBank accession no. AY567487.2) was analyzed using BLAST and MEGA4. (A), localization of ORF 3 within the hCoV-NL63 genome and comparison of nucleotide (nt) identity based on multiple sequence alignments with prototype strains of CoV groups alpha, beta, gamma. Note that IBV ORF 3a and b were fused to one ORF 3ab. (B), Summarized results of in-silico analysis on membrane topology and glycosylation (refer to Materials and Methods section). Predicted N-linked glycosylation sites are indicated by an " $\mathrm{N}$ " at the respective localizations with an index number indentifying the amino acid position. No O linked glycosylation sites were predicted.

representing the C-terminal aa 211-225 of the predicted ORF 3 protein yielded fluorescence in the cytoplasm as shown in Figure 2A and 2B (upper panel). Because colocalization of SARS-CoV ORF 3a protein with the ERGIC has been reported [36,49], the same cells were counterstained with a murine monoclonal antibody against the ERGIC53 marker protein. As shown in Figure $2 \mathrm{~A}$ and $2 \mathrm{~B}$ (upper panel) colocalization was observed in CaCo-2 and LLC-MK2 cells. Because overlapping subcellular localization was reported for SARS-
$\mathrm{CoV}$ proteins $3 \mathrm{a}$ and $\mathrm{M}$ [50], it was analyzed whether hCoV-NL63 ORF 3 and M proteins were located in the same compartment. As shown in Figure 2B (bottom panel), a strong colocalization was also seen for antiNL63 $M$ and anti-ERGIC53 signals.

Subcellular localization of transfected ORF 3 protein in human hepatocellular carcinoma cells (Huh-7) cells After showing that the ORF 3 protein can be found within the ERGIC compartment in infected cells we were interested in which other cellular compartments

Table 1 Comparison of viral proteins ORF 3 and $M$ of hCoV-NL63 and SARS-CoV ${ }^{a}$

\begin{tabular}{|c|c|c|c|c|}
\hline Viral protein & hCoV-NL63 ORF 3 & SARS-CoV ORF $3 a$ & hCoV-NL63 M & SARS-CoV M \\
\hline No. amino acids [size in kDa] & $225[26]$ & $274[31]$ & $226[26]$ & $221[25]$ \\
\hline $\begin{array}{l}\text { No. transmembrane domains } \\
\text { (position) }\end{array}$ & $3(39-61,70-92,97-116)$ & $3(34-56,77-99,103-125)$ & $\begin{array}{l}4(20-38,43-65,75-97 \\
129-151)\end{array}$ & $3(15-37,50-72,77-99)$ \\
\hline No. cysteine residues (position) & $4(72,131,137,182)$ & $\begin{array}{l}8(81,117,121,127,130 \\
133,148,157)\end{array}$ & $4(54,67,90,180)$ & $3(158,63,85)$ \\
\hline $\begin{array}{l}\text { No. putative N-glycosylation } \\
\text { sites (position) }\end{array}$ & $3(16,119,126)$ & $1\left(227^{b}\right)$ & $3(3,19,188)$ & $1\left(4^{\mathrm{C}}\right)$ \\
\hline $\begin{array}{l}\text { No. putative O-glycosylation } \\
\text { sites (position) }\end{array}$ & - & $3\left(28^{c}, 32^{c}, 267-271\right)$ & - & - \\
\hline
\end{tabular}

apositions of aa refer to accession no. NC_005831 (hCoV-NL63) and AY278491 (SARS-CoV)

${ }^{\mathrm{b}}$ Not used

'Usage confirmed 
an isolated overexpressed ORF 3 protein can be detected. Therefore we transfected Huh-7 cells and stained the ORF 3 protein with the specific antiserum and co-stained different cellular compartments with specific antibodies (mouse-anti-ERGIC53, mouse-anti-Golgi $58 \mathrm{~K}$, goat-anti-LAMP-1 for trans-Golgi/Lysosomes). As shown in Figure 3 the recombinant ORF 3 protein can be detected in all major compartments of the secretory pathway (Figure 3A for ERGIC, 3B for Golgi and 3C for trans-Golgi and lysosomes). These localizations are in concordance with recently published data on the homologous SARS-CoV ORF 3a protein that is responsible for Golgi membrane rearrangement [42].

\section{Colocalization of hCoV-NL63 ORF 3 protein with structural} proteins

For SARS-CoV ORF 3a protein, colocalization with the structural proteins $\mathrm{S}, \mathrm{E}$, and $\mathrm{M}$, but only partial colocalization with $\mathrm{N}$ has been suggested [36]. To investigate colocalization of NL63-ORF 3 protein with structural proteins, an expression plasmid containing ORF 3 with an N-terminal FLAG-tag epitope was co-transfected with vectors coding for green fluorescent protein (GFP) fused to hCoV-NL63 E, M and N proteins, respectively. Expression of proteins with correct molecular weights was confirmed by Western blot analysis (data not

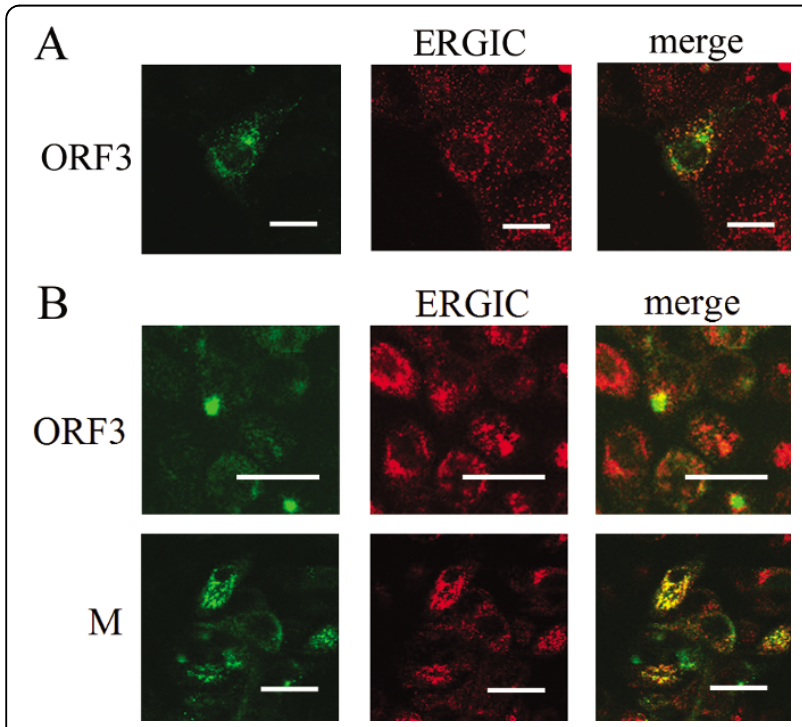

Figure 2 Subcellular localization of viral proteins in hCoV-NL63 infected CaCo-2 and LLC-MK2 cells by immunofluorescence assay. Confocal laser scanning microscopy on $\mathrm{CaCo}-2$ (A) and LLCMK2 cells (B) infected with hCoV-NL63. Left panels: staining with anti-ORF 3 and anti-M protein rabbit antisera (only in B) and detection by fluorescein isothiocyanate (FITC)-labelled goat-antirabbit antibody (green). Middle panels: detection of co-staining of the same cells with mouse-anti-ERGIC-53 mAB (Axxora) and detection with rhodamine-labelled goat-anti-mouse antibody. Yellow signals in merged pictures (right panels) show colocalization. Bars represent $20 \mu \mathrm{m}$.

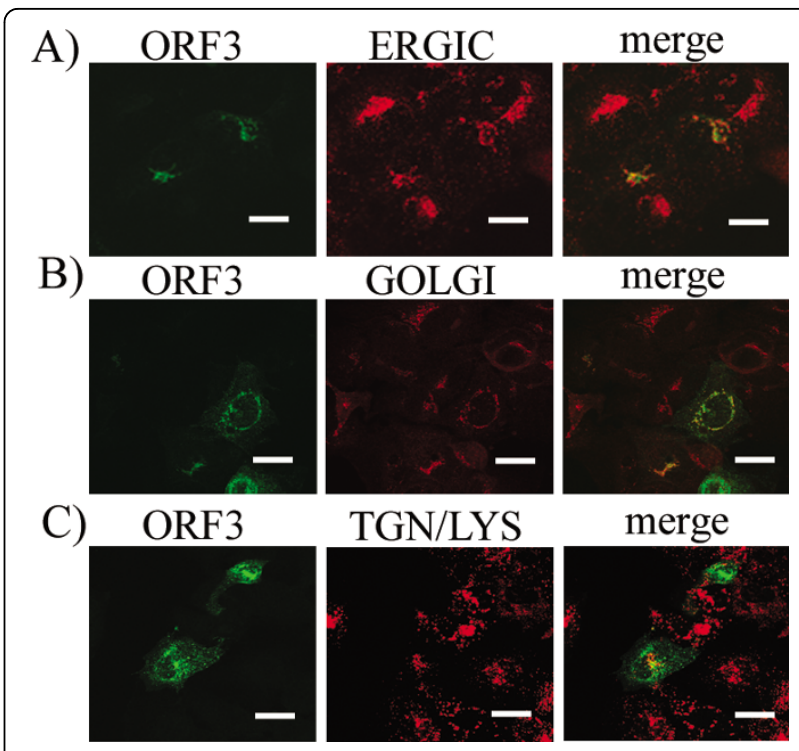

Figure 3 Subcellular localization study of overexpressed hCoVNL63 ORF 3 protein in Huh-7 cells. Confocal laser scanning microscopy on cells expressing recombinant ORF 3 protein and costaining with different antibodies for cellular organelles. Left panels: staining with rabbit-anti-ORF 3 serum and anti-rabbit-Cy2 (Dianova). Middle panels from top to bottom: co-staining of cellular organelles with a mouse-anti-ERGIC53 (A), mouse-anti-Golgi $58 \mathrm{~K}$ for the Golgi (B), goat-anti-LAMP-1 for trans-Golgi Network (TGN) and Lysosomes (LYS) together with goat (or donkey)-anti-mouse-Cy3 antibodies (C). Right panels show merged pictures where yellow areas represent colocalization. Partial colocalizations can be observed with all organelle markers indicating that the glycoprotein ORF 3 is processed trans-Golgi. Bars indicate $20 \mu \mathrm{m}$.

shown). The ERGIC compartment was stained in transfected cells as described above. As shown in Figure 4, GFP-E and GFP-M both showed extensive colocalization with FLAG-ORF 3 protein. Protein complexes were localized predominantly within the ERGIC, represented by white areas in Figure 4. GFP-N had primarily a cytosolic distribution but there were small areas of colocalization with FLAG-ORF 3 protein, within the ERGIC compartment. All experiments were done in Huh-7 cells supportive of hCoV-NL63 replication, but these same findings were also confirmed in another cell line, human embryonic kidney (HEK)-293T (data not shown).

To rule out altered subcellular localization contributed by the fusion tags on the overexpressed structural proteins, experiments were repeated using FLAG-ORF 3 protein in combination with $\mathrm{HA}$ tagged $\mathrm{E}, \mathrm{M}$ and $\mathrm{N}$ proteins in HEK-293T cells (Figure 4B). Again, colocalization of ORF 3 protein with $\mathrm{E}$ and $\mathrm{M}$ protein and, to a far lesser extent, with $\mathrm{N}$ protein was seen.

\section{Posttranslational modification of ORF 3 protein}

Posttranslational modification of the ORF 3 protein in hCoV-NL63-infected LLC-MK2 cells was analyzed by Western blot. The $M$ protein which had a very similar 


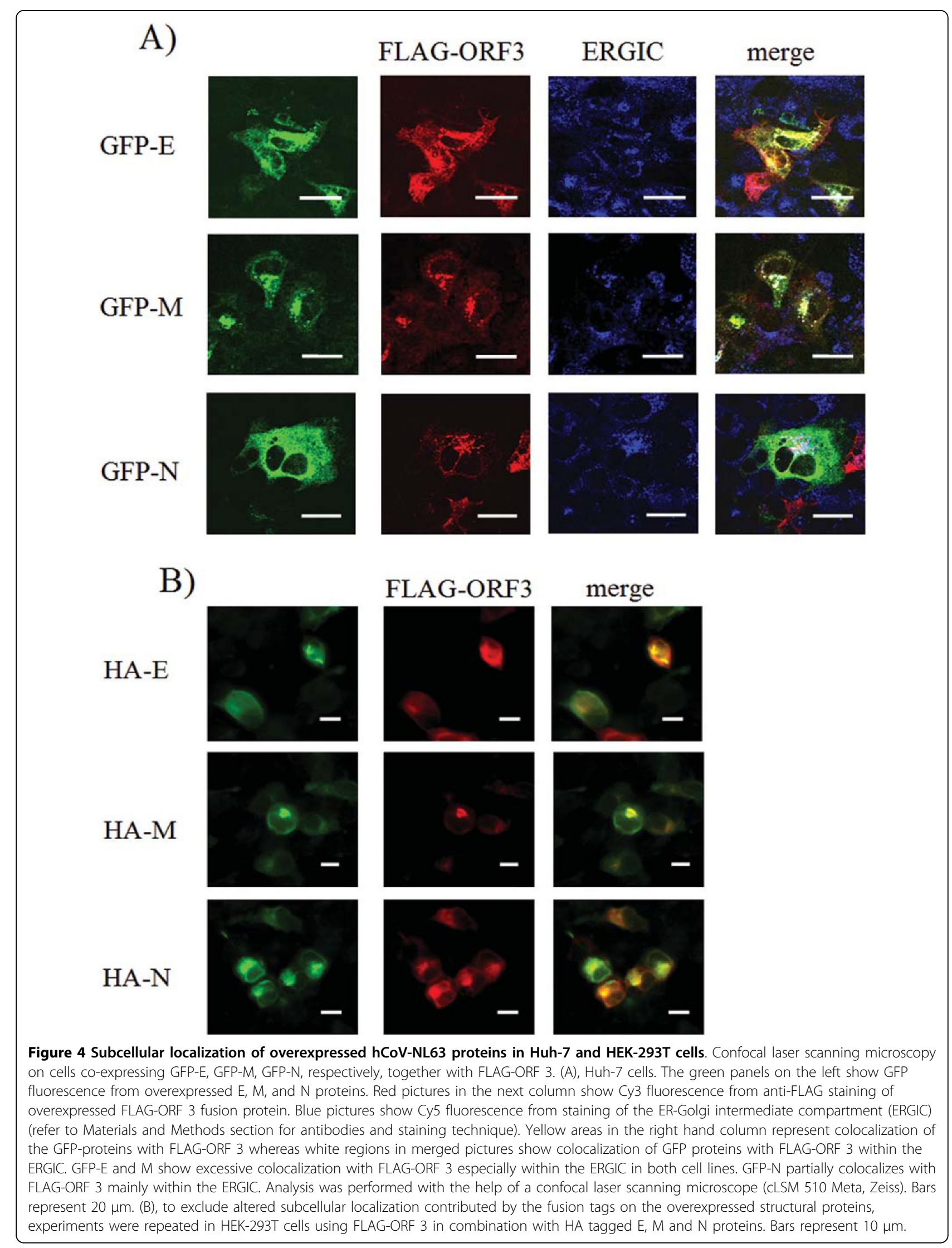


predicted molecular mass of $26 \mathrm{kDa}$ (Table 1) served as a control. As expected, the M protein and a protein corresponding to ORF 3 protein migrated at corresponding heights in Western blots (Figure 5A). Both proteins showed additional bands at slightly higher molecular mass, consistent with posttranslational modification. In contrast to virus-infected cells, cells overexpressing ORF 3 protein from plasmid with an N-terminal FLAG epitope showed only a single band in Western blot whose migration was consistent with the hypothetical unglycosylated form (Figure 5B, left panel). It was assumed that glycosylation at the predicted $\mathrm{N}$-glycosylation site at position 16 (Table 1) might be ablated in the overexpressed protein, due to presence of the N-terminal epitope tag. Indeed, recombinant ORF 3 (rORF 3) protein without any tag and overexpressed in the same cells from the same vector showed both forms, identical to those observed in virus-infected cells (Figure 5B, right panel). To determine whether $\mathrm{N}$-terminal glycosylation was to be expected at position 16, the membrane topology of the $\mathrm{N}$-terminus was examined next.

\section{Topology of ORF 3 protein}

Based on our in-silico analyses and in agreement with reports on SARS-CoV ORF 3a protein [36], we hypothesized that the hCoV-NL63 ORF 3 protein N-terminus reached the ER lumen and was eventually exposed on the cell surface. For confirmation, N-terminally FLAGtagged ORF 3 protein was overexpressed in HEK-293T cells and stained by IFA using monoclonal antibodies against the FLAG tag, or alternatively, a polyclonal antibody against a peptide representing the ORF 3 protein C-terminus. As shown in Figure 6, a perinuclear distribution of fluorescence was observed with both antibodies in permeabilized cells. In non-permeabilized cells, only the anti-FLAG antibody yielded fluorescence at cell surfaces. Unfortunately, there was no complete overlap of signals from both antibodies in fully permeabilized cells in merged fluorescence pictures, most likely due to additional non-specific recognition of non-viral epitopes by the polyclonal antibody against the ORF 3 protein Cterminus. For this reason a clear intracellular localization of the C-terminus in relation to the ER/Golgi membrane could not be formally determined. However, it could be concluded that the $\mathrm{N}$-terminus of the ORF 3 protein was facing towards the extracellular space.

\section{$\mathrm{N}$-glycosylation of in-vitro translated ORF 3}

According to in-silico predictions the ORF 3 protein contained three putative $\mathrm{N}$-glycosylation sites at positions 16, 119 and 126 (Figure 1B, Table 1). Only position 16 was considered a possible $\mathrm{N}$-glycosylation target, as the other two positions would be located within the membrane. In a vector expressing ORF 3 protein with a $\mathrm{C}$-terminal V5 tag, asparagine $(\mathrm{N})$ at position 16 was changed into glutamine $(\mathrm{Q})$. In-vitro translated ${ }^{35} \mathrm{~S}$-radiolabelled proteins with and without the exchange were treated or not treated with endoglycosidase $\mathrm{H}$ prior to SDS-PAGE analysis. SARS-CoV M protein served as the control because it had been shown previously to be Nglycosylated exclusively at position four [34]. In-vitro translated NL63 protein ORF 3 with and without the V5 tag, but not the same protein with an N16Q exchange, showed a second band of increased molecular weight in SDS-PAGE that disappeared upon endoglycosidase $\mathrm{H}$ treatment (Figure 7). In the same way as for SARS-CoV $\mathrm{M}$-protein, deglycosylation did not change the apparent molecular weight of the lower band, verifying absence of any further active glycosylation sites.

NL63-ORF 3 protein is a structural viral protein

Our data suggested that the ORF 3 protein was a glycosylated protein that colocalized with structural proteins in the ERGIC. Protein ORF 3 might thus constitute a structural protein itself. To assess if the ORF 3 protein was incorporated into virions, viral particles were purified by sucrose gradient ultracentrifugation. After
A)
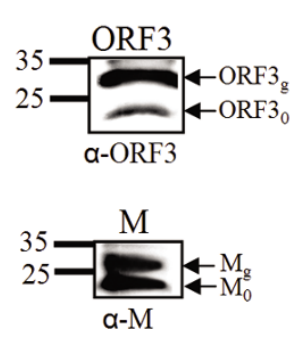

B)

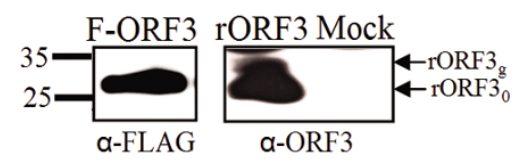

Figure 5 Comparison of ORF 3 protein in viral infection and overexpression by Western blot. (A), LLC-MK2 cells were inoculated with hCoV-NL63 (MOI 0.01) and analyzed by Western blot after 4 days using antibodies against the ORF 3 protein C-terminus (top) and against M (bottom). The bands named ORF 30 and $M_{0}$ are corresponding to the predicted molecular weights of both proteins (26 kDa). Larger bands ORF $3 \mathrm{~g}$ and $\mathrm{Mg}$ were assumed to be the result of posttranslational modification. (B, left panel): HEK-293T cells transfected with N-terminally FLAGtagged ORF 3 do not show signs of posttranslational modification as observed in (A). (B, right panel): overexpression of ORF 3 protein in the same system without an N-terminal fusion tag reconstitutes the additional band of higher molecular weight observed in infected cells. The "mock" lane represents a control transfected with an empty vector. 


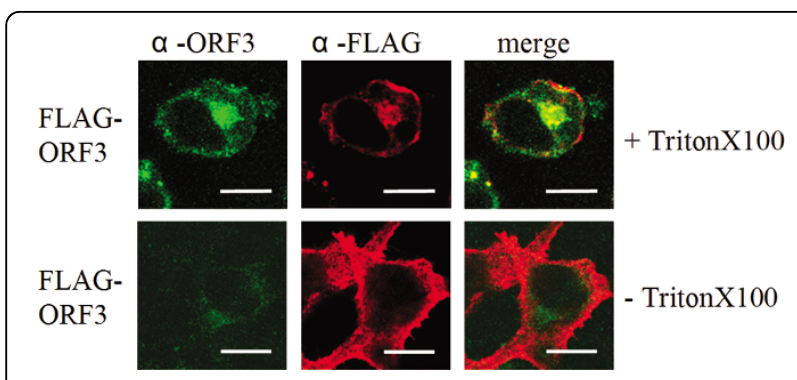

Figure 6 Topology of recombinant FLAG-tagged ORF 3 protein Recombinant N-terminal tagged FLAG-ORF 3 protein was transiently expressed in HEK-293T cells and localization was analyzed by confocal laser scanning microscopy (cLSM 510 Meta, Zeiss). FLAGORF 3 protein was stained with rabbit-anti-ORF 3 recognizing the Cterminus and mouse-anti-FLAG for detection of the FLAG-tagged Nterminus (upper panel). Permeabilized cells (+TritonX100) show colocalized signals mainly in perinuclear regions for protein ORF 3 $\mathrm{C}$-terminus and $\mathrm{N}$-terminus whereas without permeabilization (-TritonX100) only FLAG-tagged N-terminus of protein ORF 3 could be detected at the plasma membrane (lower panel). Bars represent $10 \mu \mathrm{m}$.

centrifugation, the gradient was divided into ten fractions and infectivity within each fraction was determined by plaque assay (Figure 8 ). Only fractions 4 to 7 correlating with a sucrose density of $35 \%$ to $45 \%$ contained infectious particles with a peak of $3.6 \times 10 \mathrm{E} 5 \mathrm{PFU} / \mathrm{ml}$ in fraction 5 (sucrose density 40-41\%). Subsequent Western blot analysis identified the same pattern of accumulation within the gradient for the ORF 3 protein as for the structural $\mathrm{M}$ and $\mathrm{N}$ proteins. Anti-actin staining excluded cellular contamination in these fractions. It was concluded that hCoV-NL63 ORF 3 protein was incorporated into viral particles.

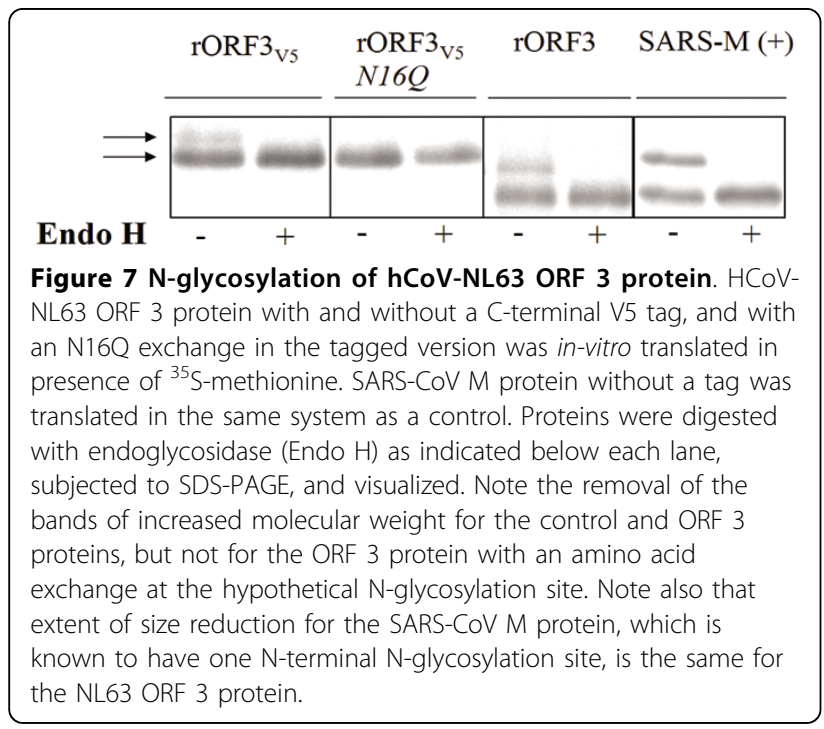

\section{Conclusions}

The ORF 3 protein and its homologues are conserved among CoVs [30]. Although identities on nt and aa level are low, most are predicted to be triple membrane-spanning proteins [35]. While it has been suggested that ORF 3 homologues are dispensable for replication in cell culture, mutations of ORF 3 homologues in transmissible gastroenteritis virus (TGEV) and porcine epidemic diarrhea virus (PEDV) lead to attenuation of virus in-vivo in pig models $[44,51,52]$. Because the SARS-ORF 3a protein underwent positive selective pressure during the human epidemic in 2002/2003 [53], an important function in-vivo can be assumed for the SARS-CoV ORF 3a protein as well.

Unfortunately, it remains difficult to characterize invivo functions of hCoV-NL63 ORF 3 protein due to lack of any animal model. However, it is interesting to note that across all strains of hCoV-NL63 characterized so far, there are no mutations in the ORF 3 amino acid

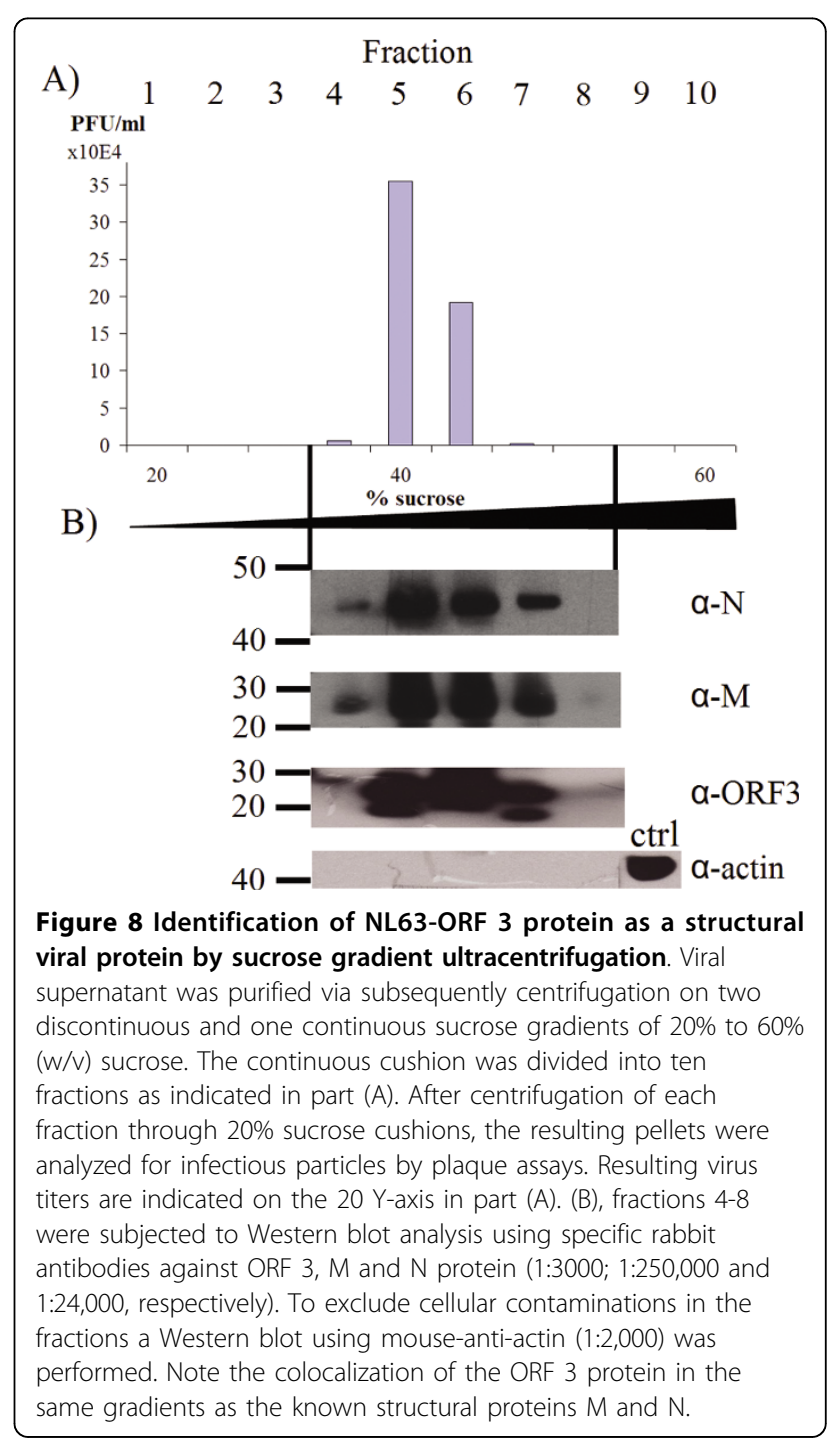


sequence $[46,54]$. Conservation of ORF 3 matches results by Donaldson et al., showing that virus production in human airway epithelium was reduced when the ORF 3 protein was replaced by GFP $[28,46]$. It has thus been suggested that protein ORF 3 might serve functions involved in viral egress which are relevant for spreading in airway epithelium but not in simpler cell culture [46].

Results from this study, in particular the subcellular localization of ORF 3 protein along the secretory pathway (ERGIC, Golgi, plasma membrane), the colocalization of NL63-ORF 3 protein with other structural proteins in the ERGIC and the inclusion of the ORF 3 protein in virions give support for a hypothetical function within the viral assembly and budding process. A range of further hypotheses can be derived from earlier investigations into protein ORF 3 functions. These include antigen decoy functions as suggested for SARS-CoV ORF 3a [55], interference with the regulation of expression of $\mathrm{NF} \kappa \mathrm{B}$-dependent cytokines [56,57] and fibrinogen [39], and finally the modulation of S protein mediated endocytosis [36] or an hypothesized down-regulation of the expression of S protein on the cell surface [58].

\section{Materials and methods \\ Cell culture and materials}

Rhesus monkey kidney LLC-MK2 cells (ATCC: CCL-7), human embryonic kidney HEK-293T cells (ATTC: CRL1573), human hepatocellular carcinoma cell line (Huh-7, JCRB0403 kindly provided by Antoine A. F. de Vries, LUMC, Leiden) and colon carcinoma $\mathrm{CaCo}-2$ cells (ATCC: HTB-37) were grown at $37^{\circ} \mathrm{C}$ and $5 \% \mathrm{CO}_{2}$ in Dulbecco's Modified Eagles Medium (DMEM; Gibco, Karlsruhe, Germany) containing 10\% fetal calf serum, 2 $\mathrm{mM}$ L-glutamine and $25 \mathrm{U}$ of penicillin/ml and $25 \mathrm{U}$ streptomycin/ml (PAA Laboratories, Linz, Austria). All cells were tested negative for mycoplasms by PCR as described elsewhere [59]. If not stated otherwise materials were provided from Roth, Karlsruhe, Germany.

\section{Virus infections with hCoV-NL63 and plaque assay}

For virus stock production either $\mathrm{CaCo}-2$ or LLC-MK2 cells were inoculated with $\mathrm{hCoV-NL63}\left(8^{\text {th }}\right.$ passage Amsterdam strain I; accession no. NC_005831) at a multiplicity of infection (MOI) of 0.01 and infected cells were cultured at $37^{\circ} \mathrm{C}$ and $5 \% \mathrm{CO}_{2}$ for five to seven days before harvesting. After centrifugation at $6,000 \times \mathrm{g}$ for $10 \mathrm{~min}$ supernatant was aliquoted and stored at $-80^{\circ} \mathrm{C}$. Titers were determined by plaque assay performed as described elsewhere [60]. Briefly, after incubation of the plaque assays at $37^{\circ} \mathrm{C}$ and $5 \% \mathrm{CO}_{2}$ for four days cells were fixed with $4 \%$ formaldehyde, stained with crystal violet solution and results were interpreted as described previously [61].

\section{Construction of plasmids}

For first strand cDNA synthesis total RNA was extracted from infected cells five to seven days post infection (dpi). Reverse transcription was performed as described elsewhere [62] using oligo(dT) primers (Fermentas, St. Leon-Roth, Germany). In order to recombinantly express $\mathrm{hCoV}-\mathrm{NL} 63$ proteins ORF $3, \mathrm{E}, \mathrm{M}$ and $\mathrm{N}$ we cloned the different genes into a variety of expression vectors. For generation of GFP-constructs PCR was performed with the following specific primers listed in Table 2: E: 5'NL63-E-GFP and 3'NL63-EpK R, M: 5'NL63-M-GFP and 3'NL63-MpK R, N: 5'NL63-N-GFP and 3'NL63-NpK R, ORF 3: 5'NL63-O3-GFP and 3'NL63-O3. For producing the pcDNA3.1-ORF 3-V5/ His construct which was used for in-vitro translation experiments we applied primers 5'Leader-NL and 3'NLO3s. Mutagenesis for the N16Q construct was done with primers NL63-O3mis-Asn16 F and R using QuickChange Mutagenesis kit (Stratagene/Agilent Technologies, Waldbronn, Germany) according to the manufacturer's instructions.

For PCR amplification of FLAG-ORF 3 as well as HA tagged $\mathrm{E}, \mathrm{M}$ and $\mathrm{N}$ and subsequent cloning into a pCAGGS vector (kindly provided by Prof. Dr. Stephan Becker, University of Marburg) we used 5'Eco-FLAG_O363 and 3'Not-O3-63, 5'Eco-HA-E and 3'Not-E, 5'Eco-HA$\mathrm{M}$ and 3'Not-M, 5'Eco-HA-N and 3'Not-N, respectively (Table 2). In this case PCR products were digested with restriction endonucleases EcoRI and NotI (Fermentas) before cloning into the pCAGGS vector (also digested and additionally dephosphorylated before use).

Generally, PCR was performed with Platinum ${ }^{\circ}$ Taq DNA Polymerase High Fidelity (Invitrogen, Karlsruhe, Germany), and conditions were as follows: $94^{\circ} \mathrm{C}$ for $2 \mathrm{~min}$, followed by 35 cycles of $94^{\circ} \mathrm{C}$ for $30 \mathrm{~s}$, primer specific temperature for $30 \mathrm{~s}$, and $72^{\circ} \mathrm{C}$ for $90 \mathrm{~s}$, with a final extension at $72^{\circ} \mathrm{C}$ for $10 \mathrm{~min}$. The different genes were cloned into pcDNA3.1/V5-His-TOPO (eukaryotic expression and invitro translation) and pcDNA3.1/NT-GFP-TOPO (eukaryotic expression) with the help of TOPO Expression Kits (Invitrogen) according to the manufacturer's instructions. Cloning of FLAG-tagged ORF 3 into the pCAGGS vector was done conventionally with T4 ligase (Invitrogen) according to suppliers' description. Correct cloning was confirmed by sequencing (Abi Prism 3,100; Applied Biosystems, Foster City, USA).

\section{Generation of polyclonal ORF 3 antiserum}

The generation of a polyclonal antiserum against ORF 3 was done with the help of keyhole limpet hemocyanin (KLH) coupled peptides. Two peptides were synthesized corresponding to aa positions 182-197 and 211-225 (Eurogentec, Seraing, Belgium). Immunization was per- 


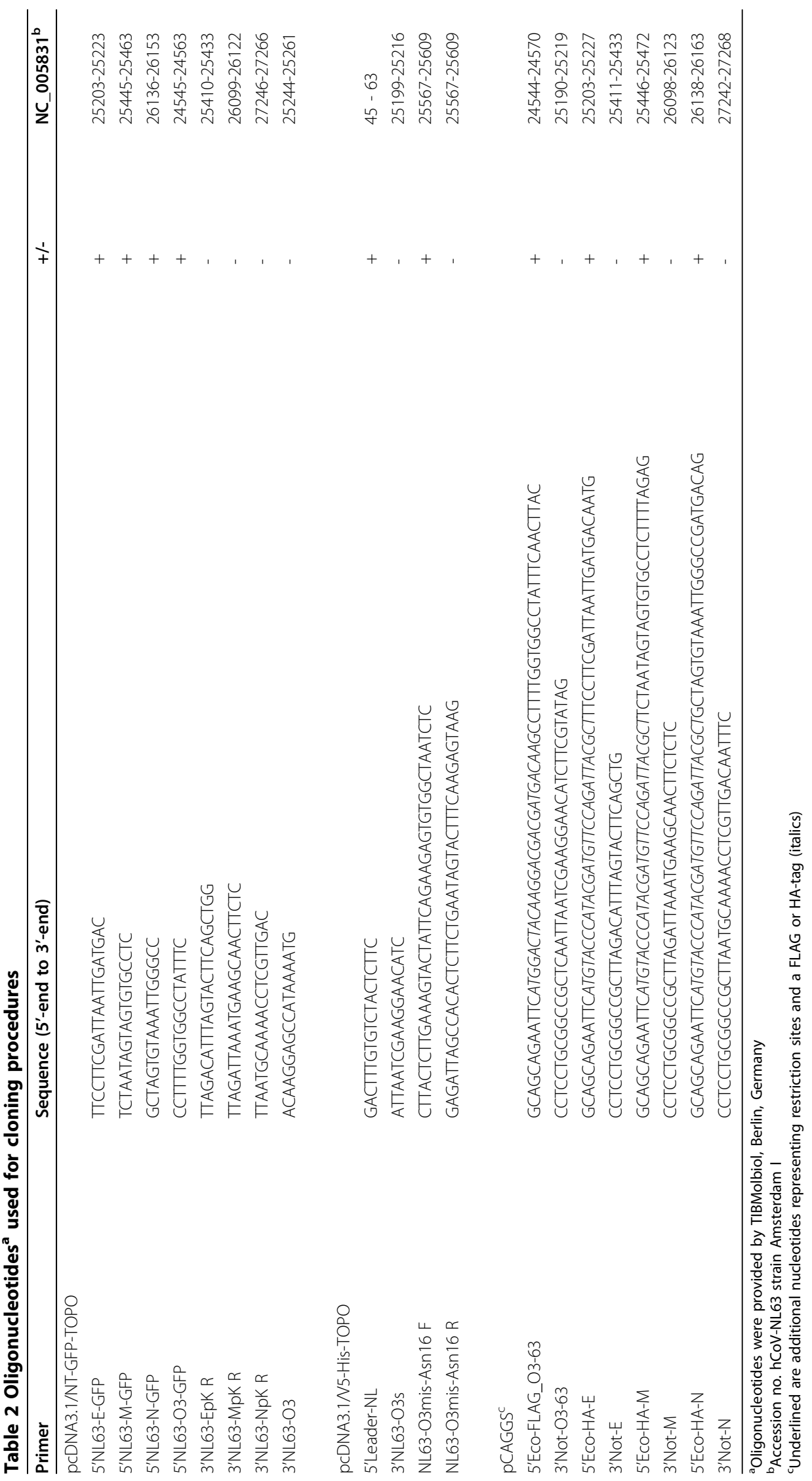


formed in-house. Briefly, a chinchilla rabbit was immunized four times with $200 \mu \mathrm{g}$ of a mixture of the two KLH coupled peptides and sera were tested as suggested by the manufacturer by enzyme-linked immunosorbent assay (ELISA) using the corresponding uncoupled peptides. We then tested serum with IFA using infected LLC-MK2 cells (Figure 2) as well as with prokaryotic recombinant proteins with the help of Dot blot and Western blot analysis (data not shown). The bleeding for the applied anti-ORF 3 serum was carried out 20 days after the fourth injection and sera were used directly.

Expression analysis and subcellular localization studies of native viral proteins by indirect IFA and Western blot

Typically, $8 \times 10^{4} \mathrm{CaCo}-2$ or LLC-MK2 cells were seeded on glass slides in a 24-well plate and infected with hCoVNL63 as described above. Two to four days after infection the cells were fixed with paraformaldehyde (4\%) for 15 min and permeabilized with $0.1 \%$ TritonX100 (Merck, Darmstadt, Germany) for $10 \mathrm{~min}$. Afterwards the cells were washed with PBS again and then incubated with the primary antibody, diluted 1:100 in sample buffer (EUROIMMUN, Lübeck, Germany), at $37^{\circ} \mathrm{C}$ for $1 \mathrm{~h}$. The ERGIC was stained with the help of mouse-anti-ERGIC53 (Axxora, Grünberg, Germany). In order to stain the Golgi apparatus we used a mouse-anti-Golgi 58 K (SigmaAldrich, Munich, Germany). For staining of the transGolgi Network and lysosomal compartment we applied a goat-anti-LAMP-1 antibody (Santa Cruz Biotechnology, Heidelberg, Germany). Secondary detection was done with fluorescein isothiocyanate (FITC) or cyanine 2 (Cy2)-conjugated goat-anti-rabbit as well as with rhodamine or Cy3-conjugated goat-anti-mouse or donkey-antigoat antibody (Dianova, Hamburg, Germany) at $37^{\circ} \mathrm{C}$ in a wet chamber for $30 \mathrm{~min}$. Slides were mounted and analyzed by cLSM 510 META laser confocal microscope (Zeiss, Jena, Germany).

Western blot analysis of viral proteins was done as described elsewhere [63]. For titration of the different rabbit antisera we used hCoV-NL63 cell lysate generated from LLC-MK2 infected cells five to seven dpi $\left(\sim 1 \times 10^{7}\right.$ cells/blot $)$ for Western blotting and incubated the produced nitrocellulose strips with the different rabbit antisera (pre-immune sera as negative control) at dilutions ranging from 1:500 up to 1:256,000 (data not shown). Generally, cells were lysed in RIPA lysis buffer $(150 \mathrm{mM} \mathrm{NaCl}, 1 \%$ Igepal CA-630, $0.5 \%$ sodium deoxycholat, $0.1 \%$ SDS, $50 \mathrm{mM}$ Tris $(\mathrm{pH}$ $8.0)$ ) and separated on a $12 \%$ SDS-PAGE gel. Western blotting was performed by using anti-ORF 3 , anti-M, anti-N at dilutions 1:4,000, 1:250,000 and 1:24,000 respectively. Secondary detection was done with the help of SuperSignal ${ }^{\circ}$ West Dura Extended or Femto Chemiluminescence Substrate (Pierce Biotechnology, Rockford, USA).
Transient transfection of recombinant proteins for colocalization studies by indirect IFA and Western blot analysis

Transfections of HEK-293T and Huh-7 cells with eukaryotic expression vectors containing the fusion genes GFP-E, GFP-M, GFP-N, HA-E, HA-M, HA-N and FLAG-ORF 3 were performed with the help of FuGENE HD (Roche, Basel, Switzerland) transfection reagent as described above using 24-well plates provided with glass slides. After a $24 \mathrm{~h}$ incubation at $37^{\circ} \mathrm{C}$ and $5 \%$ $\mathrm{CO}_{2}$ transfected cells were washed with PBS and fixed with paraformaldehyde (4\%), permeabilized with TritonX100 and incubated with rabbit-anti-FLAG (Sigma) and mouse-anti-ERGIC53 (Axxora) primary antibodies, both diluted 1:100 with sample buffer (EUROIMMUN). Secondary detection was performed with Cy3-conjugated goat-anti-rabbit (1:200) and Cy5 labelled goatanti-mouse (1:100) antibodies (Dianova). Slides were mounted and analyzed by confocal laser scanning microscopy. For Western blot analysis of recombinant ORF 3 proteins (FLAG-ORF 3, rORF 3) transfections were performed in 6-well plates using FuGENE HD transfection reagent. Transfection was performed with 6 $\mu \mathrm{g}$ DNA and $12 \mu \mathrm{l}$ FuGENE HD in $100 \mu \mathrm{l}$ DMEM. Transfected cells were washed three times with ice cold PBS and harvested for Western blot analysis after incubation for 26 to $48 \mathrm{~h}$ at $37^{\circ} \mathrm{C}$ and $5 \% \mathrm{CO}_{2}$. Cell lysis was performed with RIPA lysis buffer $\left(\sim 4 \times 10^{7}\right.$ cells/ $\mathrm{ml}$ ) containing Protease Inhibitor Cocktail III (Calbiochem, San Diego, USA) and Benzonase (25 U/ml) (Novagen, Madison, USA). After $30 \mathrm{~min}$ incubation on ice samples were sonicated twice for $30 \mathrm{~s}$ (Branson Sonifier 450, Branson, Danbury, USA) and centrifuged at $13,000 \times \mathrm{g}$ for $1 \mathrm{~min}$ at $4^{\circ} \mathrm{C}$. For detection of the different proteins we used rabbit-anti-FLAG (Sigma, diluted 1:5,000) or anti-ORF 3 antiserum (1:3000) and incubated blots for 1 to $2 \mathrm{~h}$ at room temperature. As secondary antibody we applied a goat-anti-mouse or rabbit horseradish peroxidase (HRP)-conjugated antibody (Pierce Biotechnology) for $1 \mathrm{~h}$ at room temperature. Detection was performed by using SuperSignal ${ }^{\circ}$ West Femto Chemiluminescence Substrate (Pierce Biotechnology).

In-vitro translation of ORF 3 and analysis of glycosylation by endoglycosidase $\mathrm{H}$ digestion

Plasmids pcDNA3.1-ORF 3-V5/His, pcDNA3.1-ORF 3N16Q-V5/His and pcDNA3.1-ORF 3 were employed in the TNT T7 quick coupled reticulocyte lysate system (Promega, Mannheim, Germany) according to the manufacturer's description. The proteins were metabolically labelled with $\left[{ }^{35} \mathrm{~S}\right]$ methionine (GE Healthcare, Munich, Germany) and translated in the presence of canine pancreatic microsomal membranes (Promega). Membranebound proteins were pelleted at 13,000 $\times \mathrm{g}$ for $15 \mathrm{~min}$ and resuspended in PBS. Samples were split in half and 
incubated for $1 \mathrm{~h}$ at $37^{\circ} \mathrm{C}$ with endoglycosidase $\mathrm{H}$ (Endo $\mathrm{H}$; New England Biolabs, Frankfurt, Germany) or, as control, without additives. Afterwards samples were subjected to SDS-PAGE. Radioactive signals were visualized by exposing dried gels to BioImage plates, which were scanned by using a bioimager analyzer (BAS-1,000; Fuji). Purification of viral particles by sucrose gradient ultracentrifugation

Purification of viral particles was performed by sucrose gradient ultracentrifugation as described elsewhere [33]. Briefly, $45 \mathrm{ml}$ viral supernatant from infected $\mathrm{CaCo}-2$ cells was cleared from cell debris $4 \mathrm{dpi}$ and subsequently applied onto two discontinuous and one continuous sucrose cushion of $20 \%$ to $60 \%$. The continuous cushion was divided into ten fractions and viral particles were pelleted by ultracentrifugation through a $20 \%$ sucrose cushion. Virus pellets were resuspended in $100 \mu \mathrm{L}$ PBS and stored at $-80^{\circ} \mathrm{C}$.

\section{In-silico analyses}

Prediction of protein topology and subcellular localization was done by NetNGlyc, NetOGlyc, TMHMM http://www.cbs.dtu.dk/services/, TMPred http://www.ch. embnet.org/software/TMPRED_form.html, and ProDiV/ TOPCONS http://topcons.cbr.su.se/index.php. The alignments and a sequence identity matrix were done by using BLAST and MEGA4 (BLOSUM; parameters p-distance and pair wise deletion).

\section{Acknowledgements}

This study was supported by the German Ministry of Education and Research (Project Code "Ökologie und Pathogenese von SARS"), and the European Commission (FP7 framework program No 223498 EMPERIE). We are grateful to A. Teichmann for excellent technical assistance. For providing us with Huh-7 cells we thank A. A. F. de Vries, LUMC, Leiden, The Netherlands. Special thanks to Dr. H.G. Bae, Dr. K. Madela, R. Kallies for helping with the confocal laser scanning microscopy and Dr. J. F. Drexler as well as Dr. B. Hartlieb for giving technical advice.

\section{Author details}

${ }^{1}$ University of Bonn Medical Centre, Sigmund-Freud-Str. 25, D-53127 Bonn, Germany. ${ }^{2}$ Robert Koch-Institut, Center for Biological Safety, Nordufer 20, D13353 Berlin, Germany. ${ }^{3}$ University of Amsterdam, Laboratory of Experimental Virology, Center for Infection and Immunity Amsterdam (CINIMA), Academic Medical Center, Meibergdreef 15, 1105 AZ, Amsterdam, The Netherlands. ${ }^{4}$ University of the Western Cape, Department of Medical Biosciences, Private Bag X17 Bellville 7535, Republic of South Africa.

\section{Authors' contributions}

MAM, MN, CD conceived and performed the experiments DV, OB, DL, ARS, SK, TS, LvdH, BCF; assisted in experiments and contributed reagents. MAM; CD wrote the manuscript. All authors have read and approved the final manuscript.

\section{Competing interests}

The authors declare that they have no competing interests.

Received: 29 September 2009

Accepted: 15 January 2010 Published: 15 January 2010

\section{References}

1. Hoek van der L, Pyrc K, Jebbink MF, Vermeulen-Oost W, Berkhout RJ, Wolthers KC, Wertheim-van Dillen PM, Kaandorp J, Spaargaren J,
Berkhout B: Identification of a new human coronavirus. Nat Med 2004 10:368-373.

2. Hofmann H, Pyrc K, Hoek van der L, Geier M, Berkhout B, Pohlmann S: Human coronavirus NL63 employs the severe acute respiratory syndrome coronavirus receptor for cellular entry. Proc Natl Acad Sci USA 2005, 102:7988-7993

3. Han TH, Chung JY, Kim SW, Hwang ES: Human Coronavirus-NL63 infections in Korean children, 2004-2006. J Clin Virol 2007, 38:27-31.

4. Vabret A, Mourez T, Dina J, Hoek van der L, Gouarin S, Petitjean J, Brouard J, Freymuth F: Human coronavirus NL63, France. Emerg Infect Dis 2005, 11:1225-1229.

5. Pyrc K, Berkhout B, Hoek van der L: The novel human coronaviruses NL63 and HKU1. J Virol 2007, 81:3051-3057.

6. Hoek van der L, Sure K, Ihorst G, Stang A, Pyrc K, Jebbink MF, Petersen G, Forster J, Berkhout $B$, Uberla $K$ : Croup is associated with the novel coronavirus NL63. PLoS Med 2005, 2:e240.

7. Masters PS: The molecular biology of coronaviruses. Adv Virus Res 2006, 66:193-292.

8. Klumperman J, Locker JK, Meijer A, Horzinek MC, Geuze HJ, Rottier PJ: Coronavirus M proteins accumulate in the Golgi complex beyond the site of virion budding. J Virol 1994, 68:6523-6534.

9. Tooze J, Tooze S, Warren G: Replication of coronavirus MHV-A59 in saccells: determination of the first site of budding of progeny virions. Eur J Cell Biol 1984, 33:281-293.

10. Escors D, Ortego J, Laude $H$, Enjuanes L: The membrane M protein carboxy terminus binds to transmissible gastroenteritis coronavirus core and contributes to core stability. J Virol 2001, 75:1312-1324.

11. Locker JK, Opstelten DJ, Ericsson M, Horzinek MC, Rottier PJ: Oligomerization of a trans-Golgi/trans-Golgi network retained protein occurs in the Golgi complex and may be part of its retention. J Biol Chem 1995, 270:8815-8821.

12. Lontok E, Corse E, Machamer CE: Intracellular targeting signals contribute to localization of coronavirus spike proteins near the virus assembly site. J Virol 2004, 78:5913-5922.

13. Opstelten DJ, Raamsman MJ, Wolfs K, Horzinek MC, Rottier PJ: Coexpression and association of the spike protein and the membrane protein of mouse hepatitis virus. Adv Exp Med Biol 1995, 380:291-297.

14. Corse $E$, Machamer CE: The cytoplasmic tails of infectious bronchitis virus $E$ and $M$ proteins mediate their interaction. Virology 2003, 312:25-34.

15. Raamsman MJ, Locker JK, de Hooge A, de Vries AA, Griffiths G, Vennema H, Rottier PJ: Characterization of the coronavirus mouse hepatitis virus strain A59 small membrane protein E. J Virol 2000, 74:2333-2342.

16. Nal B, Chan C, Kien F, Siu L, Tse J, Chu K, Kam J, Staropoli I, CrescenzoChaigne $B$, Escriou N, et al: Differential maturation and subcellular localization of severe acute respiratory syndrome coronavirus surface proteins S, M and E. J Gen Virol 2005, 86:1423-1434.

17. Alexander S, Elder JH: Carbohydrate dramatically influences immune reactivity of antisera to viral glycoprotein antigens. Science 1984, 226:1328-1330.

18. Braakman I, van Anken E: Folding of viral envelope glycoproteins in the endoplasmic reticulum. Traffic 2000, 1:533-539.

19. de Haan CA, de Wit M, Kuo L, Montalto-Morrison C, Haagmans BL, Weiss SR, Masters PS, Rottier PJ: The glycosylation status of the murine hepatitis coronavirus $\mathrm{M}$ protein affects the interferogenic capacity of the virus in vitro and its ability to replicate in the liver but not the brain. Virology 2003, 312:395-406.

20. Wissink EH, Kroese MV, Maneschijn-Bonsing JG, Meulenberg JJ, van Rijn PA, Rijsewijk FA, Rottier PJ: Significance of the oligosaccharides of the porcine reproductive and respiratory syndrome virus glycoproteins GP2a and GP5 for infectious virus production. J Gen Virol 2004, 85:3715-3723.

21. de Haan CA, Masters PS, Shen X, Weiss S, Rottier PJ: The group-specific murine coronavirus genes are not essential, but their deletion, by reverse genetics, is attenuating in the natural host. Virology 2002, 296:177-189.

22. Ortego J, Sola I, Almazan F, Ceriani JE, Riquelme C, Balasch M, Plana J, Enjuanes L: Transmissible gastroenteritis coronavirus gene 7 is not essential but influences in vivo virus replication and virulence. Virology 2003, 308:13-22.

23. Herrewegh AA, Vennema H, Horzinek MC, Rottier PJ, de Groot RJ: The molecular genetics of feline coronaviruses: comparative sequence 
analysis of the ORF7a/7b transcription unit of different biotypes. Virology 1995, 212:622-631.

24. Haijema BJ, Volders H, Rottier PJ: Live, attenuated coronavirus vaccines through the directed deletion of group-specific genes provide protection against feline infectious peritonitis. J Virol 2004, 78:3863-3871.

25. Snijder EJ, Bredenbeek PJ, Dobbe JC, Thiel V, Ziebuhr J, Poon LL, Guan Y, Rozanov M, Spaan WJ, Gorbalenya AE: Unique and conserved features of genome and proteome of SARS-coronavirus, an early split-off from the coronavirus group 2 lineage. J Mol Biol 2003, 331:991-1004.

26. Frieman MB, Yount B, Sims AC, Deming DJ, Morrison TE, Sparks J, Denison M, Heise M, Baric RS: SARS coronavirus accessory ORFs encode luxury functions. Adv Exp Med Biol 2006, 581:149-152.

27. Pfefferle $S$, Krahling V, Ditt V, Grywna K, Muhlberger E, Drosten C: Reverse genetic characterization of the natural genomic deletion in SARSCoronavirus strain Frankfurt-1 open reading frame $7 \mathrm{~b}$ reveals an attenuating function of the $7 \mathrm{~b}$ protein in-vitro and in-vivo. Virol J 2009, 6:131.

28. Yount B, Roberts RS, Sims AC, Deming D, Frieman MB, Sparks J, Denison MR, Davis N, Baric RS: Severe acute respiratory syndrome coronavirus group-specific open reading frames encode nonessential functions for replication in cell cultures and mice. J Virol 2005, 79:1490914922.

29. Schaecher SR, Touchette E, Schriewer J, Buller RM, Pekosz A: Severe acute respiratory syndrome coronavirus gene 7 products contribute to virusinduced apoptosis. J Virol 2007, 81:11054-11068.

30. Tang XC, Zhang JX, Zhang SY, Wang P, Fan XH, Li LF, Li G, Dong BQ, Liu W, Cheung $\mathrm{CL}$, et al: Prevalence and genetic diversity of coronaviruses in bats from China. J Virol 2006, 80:7481-7490.

31. Akerstrom S, Tan YJ, Mirazimi A: Amino acids 15-28 in the ectodomain of SARS coronavirus 3a protein induces neutralizing antibodies. FEBS Lett 2006, 580:3799-3803.

32. Ito N, Mossel EC, Narayanan K, Popov VL, Huang C, Inoue T, Peters CJ, Makino S: Severe acute respiratory syndrome coronavirus 3a protein is a viral structural protein. J Virol 2005, 79:3182-3186.

33. Shen S, Lin PS, Chao YC, Zhang A, Yang X, Lim SG, Hong W, Tan YJ: The severe acute respiratory syndrome coronavirus $3 a$ is a novel structural protein. Biochem Biophys Res Commun 2005, 330:286-292.

34. Voss D, Kern A, Traggiai E, Eickmann M, Stadler K, Lanzavecchia A, Becker S: Characterization of severe acute respiratory syndrome coronavirus membrane protein. FEBS Lett 2006, 580:968-973.

35. Oostra M, de Haan CA, de Groot RJ, Rottier PJ: Glycosylation of the severe acute respiratory syndrome coronavirus triple-spanning membrane proteins 3a and M. J Virol 2006, 80:2326-2336

36. Tan YJ, Teng E, Shen S, Tan TH, Goh PY, Fielding BC, Ooi EE, Tan HC, Lim SG, Hong W: A novel severe acute respiratory syndrome coronavirus protein, $\mathrm{U} 274$, is transported to the cell surface and undergoes endocytosis. J Virol 2004, 78:6723-6734.

37. Law PT, Wong CH, Au TC, Chuck CP, Kong SK, Chan PK, To KF, Lo AW Chan JY, Suen $Y K$, et al: The 3a protein of severe acute respiratory syndrome-associated coronavirus induces apoptosis in Vero E6 cells. J Gen Virol 2005, 86:1921-1930.

38. Yuan X, Yao Z, Wu J, Zhou Y, Shan Y, Dong B, Zhao Z, Hua P, Chen J, Cong Y: G1 phase cell cycle arrest induced by SARS-CoV 3a protein via the cyclin D3/pRb pathway. Am J Respir Cell Mol Biol 2007, 37:9-19.

39. Tan YJ, Tham PY, Chan DZ, Chou CF, Shen S, Fielding BC, Tan TH, Lim SG, Hong W: The severe acute respiratory syndrome coronavirus 3a protein up-regulates expression of fibrinogen in lung epithelial cells. J Virol 2005, 79:10083-10087.

40. Akerstrom S, Mirazimi A, Tan YJ: Inhibition of SARS-CoV replication cycle by small interference RNAs silencing specific SARS proteins, 7a/7b, 3a/ $3 \mathrm{~b}$ and S. Antiviral Res 2007, 73:219-227.

41. Lu W, Zheng BJ, Xu K, Schwarz W, Du L, Wong CK, Chen J, Duan S, Deubel V, Sun B: Severe acute respiratory syndrome-associated coronavirus 3 a protein forms an ion channel and modulates virus release. Proc Natl Acad Sci USA 2006, 103:12540-12545.

42. Freundt EC, Yu L, Goldsmith CS, Welsh S, Cheng A, Yount B, Liu W, Frieman MB, Buchholz UJ, Screaton GR, et al: The ORF 3a Protein of SARSCoV Promotes Membrane Rearrangement and Cell Death. J Virol 2009.

43. Andries K, Pensaert M: Vomiting and wasting disease, a coronavirus infection of pigs. Adv Exp Med Biol 1981, 142:399-408.
44. Song DS, Yang JS, Oh JS, Han JH, Park BK: Differentiation of a Vero cell adapted porcine epidemic diarrhea virus from Korean field strains by restriction fragment length polymorphism analysis of ORF 3. Vaccine 2003, 21:1833-1842.

45. Woods RD: Efficacy of a transmissible gastroenteritis coronavirus with an altered ORF-3 gene. Can J Vet Res 2001, 65:28-32.

46. Donaldson EF, Yount B, Sims AC, Burkett S, Pickles RJ, Baric RS: Systematic assembly of a full-length infectious clone of human coronavirus NL63. J Virol 2008, 82:11948-11957.

47. Dijkman R, Jebbink MF, Wilbrink B, Pyrc K, Zaaijer HL, Minor PD, Franklin S, Berkhout B, Thiel V, Hoek van der L: Human coronavirus $229 \mathrm{E}$ encodes a single ORF4 protein between the spike and the envelope genes. Virol J 2006, 3:106.

48. Fielding BC, Suliman T: Comparative analysis of human coronavirus-NL63 ORF3 protein homologues. African Journal of Biotechnology 2009, 8:31753178.

49. Yu CJ, Chen YC, Hsiao CH, Kuo TC, Chang SC, Lu CY, Wei WC, Lee CH, Huang LM, Chang MF, et al: Identification of a novel protein 3a from severe acute respiratory syndrome coronavirus. FEBS Lett 2004, 565:111116.

50. Yuan X, Li J, Shan Y, Yang Z, Zhao Z, Chen B, Yao Z, Dong B, Wang S, Chen J, Cong $Y$ : Subcellular localization and membrane association of SARS-CoV 3a protein. Virus Res 2005, 109:191-202.

51. Duarte M, Tobler K, Bridgen A, Rasschaert D, Ackermann M, Laude H: Sequence analysis of the porcine epidemic diarrhea virus genome between the nucleocapsid and spike protein genes reveals a polymorphic ORF. Virology 1994, 198:466-476.

52. McGoldrick A, Lowings JP, Paton DJ: Characterisation of a recent virulent transmissible gastroenteritis virus from Britain with a deleted ORF 3 a. Arch Virol 1999, 144:763-770.

53. Tang $X, L i$ G, Vasilakis $N$, Zhang $Y$, Shi Z, Zhong $Y$, Wang LF, Zhang S: Differential stepwise evolution of SARS coronavirus functional proteins in different host species. BMC Evol Biol 2009, 9:52.

54. Pyrc K, Dijkman R, Deng L, Jebbink MF, Ross HA, Berkhout B, Hoek van der $\mathrm{L}$ : Mosaic structure of human coronavirus NL63, one thousand years of evolution. J Mol Biol 2006, 364:964-973.

55. Huang C, Narayanan K, Ito N, Peters CJ, Makino S: Severe acute respiratory syndrome coronavirus 3 a protein is released in membranous structures from 3a protein-expressing cells and infected cells. J Virol 2006, 80:210217.

56. Narayanan K, Huang C, Makino S: SARS coronavirus accessory proteins. Virus Res 2008, 133:113-121.

57. Kanzawa N, Nishigaki K, Hayashi T, Ishii Y, Furukawa S, Niiro A, Yasui F, Kohara M, Morita K, Matsushima K, et al: Augmentation of chemokine production by severe acute respiratory syndrome coronavirus $3 \mathrm{a} / \mathrm{X} 1$ and $7 \mathrm{a} / \mathrm{X} 4$ proteins through NF-kappaB activation. FEBS Lett 2006, 580:68076812.

58. Tan YJ, Lim SG, Hong W: Understanding the accessory viral proteins unique to the severe acute respiratory syndrome (SARS) coronavirus. Antiviral Res 2006, 72:78-88.

59. van Kuppeveld FJ, Melchers WJ, Willemse HF, Kissing J, Galama JM, Logt van der JT: Detection of Mycoplasma pulmonis in experimentally infected laboratory rats by $16 \mathrm{~S}$ rRNA amplification. J Clin Microbiol 1993, 31:524-527.

60. Herzog P, Drosten C, Muller MA: Plaque assay for human coronavirus NL63 using human colon carcinoma cells. Virol J 2008, 5:138.

61. Niedrig M, Lademann M, Emmerich P, Lafrenz M: Assessment of IgG antibodies against yellow fever virus after vaccination with 17D by different assays: neutralization test, haemagglutination inhibition test, immunofluorescence assay and ELISA. Trop Med Int Health 1999, 4:867871.

62. Hattermann K, Muller MA, Nitsche A, Wendt S, Donoso Mantke O, Niedrig M: Susceptibility of different eukaryotic cell lines to SARScoronavirus. Arch Virol 2005, 150:1023-1031.

63. Muller MA, Paweska JT, Leman PA, Drosten C, Grywna K, Kemp A, Braack L, Sonnenberg K, Niedrig M, Swanepoel R: Coronavirus antibodies in African bat species. Emerg Infect Dis 2007, 13:1367-1370.

doi:10.1186/1743-422X-7-6

Cite this article as: Müller et al: Human Coronavirus NL63 Open Reading Frame 3 encodes a virion-incorporated $\mathrm{N}$-glycosylated membrane protein. Virology Journal 2010 7:6. 